\title{
Hypoxia-induced lactate dehydrogenase A protects cells from apoptosis in endometriosis
}

\author{
JINYAN ZHENG ${ }^{1-3^{*}}$, YONGDONG DAI $^{1,2^{*}}$, XIANG LIN $^{1,2}$, QIANMENG HUANG $^{1,2}$, LIBING SHI $^{1,2}$,

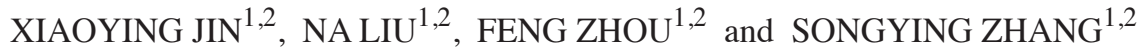 \\ ${ }^{1}$ Assisted Reproduction Unit, Department of Obstetrics and Gynecology, ${ }^{2}$ Key Laboratory of \\ Reproductive Dysfunction Management of Zhejiang Province, Sir Run Run Shaw Hospital, \\ Zhejiang University School of Medicine, Hangzhou, Zhejiang 310016; ${ }^{3}$ Department of Obstetrics, \\ Sanmen People's Hospital of Zhejiang, Taizhou, Zhejiang 317100, P.R. China
}

Received January 8, 2020; Accepted April 7, 2021

DOI: $10.3892 / \mathrm{mmr} .2021 .12276$

\begin{abstract}
The pathological expression and function of lactate dehydrogenase A (LDHA), a key enzyme that converts pyruvate into lactic acid during glycolysis, remains unknown in endometriosis. In the present study, LDHA expression in tissue samples was determined by immunohistochemistry. To examine whether LDHA was induced by hypoxia, primary cultured endometrial stromal cells (ESCs) and glandular epithelial Ishikawa cells were exposed to $1 \% \mathrm{O}_{2}$ (hypoxia) or $21 \% \mathrm{O}_{2}$ (normoxia). Cellular functions were assessed by flow cytometry, Transwell and Cell Counting Kit- 8 assays in LDHA-silenced ESCs and Ishikawa cells. Mitochondrial functions were evaluated using mitochondrial membrane potential JC-1 staining, reactive oxygen species flow cytometric analysis and ATP detection. Additionally, lactic acid production was examined and western blotting was used to evaluate the expression levels of proteins associated with apoptosis, cell cycle and glycolysis, as well as regulatory proteins involved in epithelial-mesenchymal transformation and glycolytic pathways. LDHA was localized to endometrial glandular cells and stromal cells. However, LDHA protein expression was higher in endometriotic lesions compared with that in normal and eutopic endometria. LDHA expression levels in ectopic glandular cells were higher during the proliferative stage compared with during the secretory stage. Hypoxia treatment of Ishikawa cells and ESCs markedly induced the
\end{abstract}

Correspondence to: Professor Songying Zhang, Assisted Reproduction Unit, Department of Obstetrics and Gynecology, Sir Run Run Shaw Hospital, Zhejiang University School of Medicine, 3 Qingchun East Road, Jianggan, Hangzhou, Zhejiang 310016, P.R. China

E-mail: zhangsongying@zju.edu.cn

${ }^{*}$ Contributed equally

Key words: endometriosis, lactate dehydrogenase A, hypoxiainducible factor $1 \alpha$, hypoxia, glycolysis
mRNA and protein expression of LDHA. Silencing of LDHA expression in Ishikawa cells and THESC cells significantly promoted impaired mitochondrial function and apoptosis while inhibiting migration and glycolysis. However, it had no obvious effect on proliferation. In conclusion, the present study revealed that LDHA was highly expressed in endometriotic tissues, where it may serve a notable role in the occurrence and development of endometriosis.

\section{Introduction}

Endometriosis is a common benign disease in women, which is characterized by endometrial tissue (glands and stroma) appearing outside the uterus. Endometriosis is associated with chronic pelvic pain, dysmenorrhea, dyspareunia and infertility (1). Numerous theories and hypotheses have attempted to explain the pathogenesis of endometriosis, and the most widely accepted theory is that endometriosis results from retrograde menstruation $(2,3)$. During menstruation, glandular epithelium and endometrial mesenchymal cells can enter the pelvic cavity through the fallopian tube, where they implant in the ovary or adjacent pelvic peritoneum, and continue to proliferate and spread to form an endometriotic lesion (4).

According to Sampson's theory, retrograde endometrial fragments suffer from heavier hypoxic stress compared with their eutopic tissues $(5,6)$. Hypoxia inducible factor (HIF)-1 $\alpha$ is a key regulator of hypoxia, which makes it a useful marker of cellular hypoxic stress. Our previous studies revealed that HIF-1 $\alpha$ expression was increased in ectopic lesions compared with that in eutopic tissues and normal endometrium $(7,8)$. Ectopic endometrial cells may ultimately use the hypoxic microenvironment to promote cell adhesion, proliferation and angiogenesis $(5,6)$; however, how ectopic cells convert the metabolism to overcome and adapt to hypoxic microenvironments before new vasculature forms in ectopic lesions is not clear. Several studies have suggested that the Warburg-like effect, a shift in cell metabolism from mitochondrial oxidative phosphorylation to aerobic glycolysis that favors tumor progression, may be induced by transforming growth factor $\beta 1$ to promote the development of endometriosis $(9,10)$. Pyruvate dehydrogenase kinase 1 (PDK1), a critical enzyme 
for regulating hypoxia-induced glucose metabolism, has been reported to alter cellular metabolism and to inhibit apoptosis in endometriotic stromal cells (11). Whether other glycolysis regulators are involved in the growth of ectopic lesions is, to the best of our knowledge, unknown.

Lactate dehydrogenase A (LDHA) converts pyruvate to lactic acid during the last step of glycolysis. Increased expression of LDHA is required for the maintenance of glycolysis, and has been associated with the evolution of aggressive and metastatic cancer in a variety of tumor types, including pancreatic cancer (12), squamous cell carcinoma of the head and neck (13), and non-Hodgkin's cell lymphoma (14). Silencing of LDHA has been shown to significantly attenuate the colony-forming ability and invasive capacity of cervical cancer cells (15). In endometriosis, LDHA expression has been reported to be significantly increased in endometriosis lesions compared with that in eutopic endometrium from women with endometriosis (9). However, the underlying mechanism of the elevated regulation of LDHA in endometriotic cells and cellular functions remains to be investigated.

LDHA is one of the important rate-limiting enzymes in the glycometabolism pathway (16). Myc and HIF can regulate the expression of LDHA at the level of transcription and translation (17). HIF-1 $\alpha$ increases glycolysis and promotes lactic acid production through the PI3k/Akt/mTOR pathway and can be upregulated by combining with the promoter of LDHA $(17,18)$. HIF is a key transcription factor that mediates the cell response to hypoxia, which plays a notable role in the adaptation of ectopic endometrial cells to hypoxia (19). Previous studies have shown that HIF- $1 \alpha$ is a determinant of tumor development, and is associated with tumor invasion, metastasis and prognosis $(20,21)$. In addition, HIF-1 $\alpha$ expression has been reported to be increased in endometriosis, where it can induce vascular endothelial growth factor, leptin, cysteine-rich angiogenic inducer, osteopontin and other factors to promote the establishment of an effective vascular network, and the occurrence and development of endometriosis (5,22-24). HIF-1 $\alpha$ may also activate the expression of glycolysis pathway-related genes, such as LDHA, phosphoglycerate kinase 1 and pyruvate kinase M2, by binding to hypoxia response elements (25). Given that HIF-1 $\alpha$ and LDHA are coincidently expressed in endometriotic lesions (9) and their functions are strongly associated with hypoxia in other diseases, it was hypothesized that hypoxia-induced LDHA may serve a notable role in the development of endometriosis. The present study compared the expression of LDHA in normal endometrium, eutopic endometrium and ectopic lesions, and explored the function of LDHA in endometriotic cells.

\section{Materials and methods}

Study approval and sample collection. The present study was initiated on May 1, 2018 and was terminated on April 30, 2019 at the Department of Obstetrics and Gynecology, Sir Run Run Shaw Hospital, Zhejiang University School of Medicine (Hangzhou, China). All patients provided written informed consent before sample collection. Endometriosis was confirmed by pathologists of Sir Run Run Shaw Hospital who were not involved in the study. Endometriosis was classified according to the revised American Society for Reproductive Medicine scoring system (26). Patients with no hormone treatment 6 months prior to gynecological surgery were included. Individuals with other endocrine diseases or diseases associated with the uterus or ovaries, such as uterine cavity polyps and uterine fibroids, were excluded. Both eutopic and ectopic endometrium specimens of peritoneal endometriosis were collected. Endometrial fragments obtained from patients with another benign gynecological disease were recruited as normal controls. The baseline data of the included patients are presented in Table I. The present study was approved by The Ethics Committee of Sir Run Run Shaw Hospital at Zhejiang University. A total of 35 normal endometrial tissues, 39 eutopic tissues and 62 ectopic lesions were examined. Paired eutopic and ectopic tissues were collected from 25 patients with endometriosis; in total, tissues were obtained from 111 patients, of which 35 were normal control individuals, in the present study.

Isolation, purification, culture and authentication of endometrial stromal cells (ESCS). The protocol for isolation of ESCs from patients with or without endometriosis was performed as previously described (27). In brief, clinical specimens were washed with PBS, cut into small fragments in DMEM/nutrient mixture F-12 (F12) (cat. no. MA0590; Meilunbio) and digested with collagenase I (cat. no. C0130; Sigma-Aldrich; Merck KGaA) for $>1 \mathrm{~h}$ at $37^{\circ} \mathrm{C}$. The resulting cell suspension was filtered and centrifuged at $800 \mathrm{x} \mathrm{g}$ for $5 \mathrm{~min}$, at room temperature. Pelleted cells were cultured in DMEM/F12 supplemented with 10\% FBS (cat. no. 10099; Gibco; Thermo Fisher Scientific, Inc.), penicillin (66.67 mg/l) and streptomycin $(100 \mathrm{mg} / \mathrm{l})$ in a humidified atmosphere of $5 \% \mathrm{CO}_{2}$ at $37^{\circ} \mathrm{C}$. For hypoxic treatment, cells were incubated in a hypoxia chamber with $1 \% \mathrm{O}_{2}, 94 \% \mathrm{~N}_{2}$ and $5 \% \mathrm{CO}_{2}$ at $37^{\circ} \mathrm{C}(28,29)$. Cells were incubated in a hypoxia chamber for $0,2,4,8,12,24$ and 48 h. Immunofluorescent authentication of ESCs was then conducted. Briefly, primary cultured cells were cultured on coverslips (cell confluence, 30-50\%), washed gently with PBS twice and fixed with $4 \%$ paraformaldehyde (cat. no. P1110; Beijing Solarbio Science \& Technology Co., Ltd.) for $20 \mathrm{~min}$ at room temperature. After permeabilization with PBS- $0.1 \%$ Triton X-100 for $10 \mathrm{~min}$ at $4^{\circ} \mathrm{C}$, cells were blocked with 5\% BSA (cat. no. AR0004; Wuhan Boster Biological Technology Co., Ltd) for $30 \mathrm{~min}$ at room temperature and then incubated with vimentin (cat. no. 5741; 1:100; Cell Signaling Technology, Inc.) and pan-cytokeratin (cat. no. ab215838; 1:500; Abcam) at $4^{\circ} \mathrm{C}$ overnight. Fluorescent-conjugated secondary antibody solution [1:100; green fluorescence, cat. no. 70-GAR4882; red fluorescence, cat. no. 70-GAR5492; Hangzhou Multi Sciences (Lianke) Biotech Co., Ltd.] at room temperature in the dark for $30 \mathrm{~min}$ was used to visualize the signal. DAPI solution (cat. no. H-1200; Vector Laboratories) was used to stain cell nuclei. Images were captured under a fluorescence microscope (Olympus BX51; Olympus Corporation). Cell identification is shown in Fig. S1.

Immunohistochemistry assay. Tissue samples were fixed with $4 \%$ paraformaldehyde for $24 \mathrm{~h}$ at room temperature, embedded in paraffin, sliced into $5-\mu \mathrm{m}$ sections and stained 
Table I. Baseline data for cases included in the study.

\begin{tabular}{lrrr}
\hline Characteristic & Normal & Endometriosis & P-value $^{\mathrm{a}}$ \\
\hline Age, years & $30.88 \pm 4.10$ & $30.99 \pm 4.8$ & 0.818 \\
Body mass index, $\mathrm{kg} / \mathrm{m}^{2}$ & $21.70 \pm 2.37$ & $20.97 \pm 2.71$ & 0.053 \\
Age of menarche, years & $14.20 \pm 1.12$ & $14.12 \pm 1.10$ & 0.824 \\
Menstrual cycle, days & $31.68 \pm 5.57$ & $29.49 \pm 5.81$ & 0.078 \\
Menstrual period, days & $5.42 \pm 1.17$ & $6.12 \pm 1.17$ & 0.004 \\
\hline
\end{tabular}

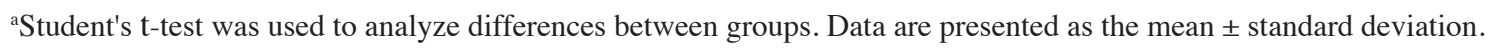

according to standard immunohistochemical staining procedures with an antibody against LDHA (cat. no. 3582S; Cell Signaling Technology, Inc.). Briefly, the tissue sections were immersed in blocking reagent $(500 \mathrm{ml}$ methanol $+0.5 \mathrm{ml}$ $3 \%$ hydrogen peroxide) and incubated at room temperature for $5 \mathrm{~min}$, then boiled in citrate buffer (cat. no. C1010-2L; Beijing Solarbio Science \& Technology Co., Ltd.) for $2.5 \mathrm{~min}$ and sealed with 5\% BSA at room temperature in the dark for $30 \mathrm{~min}$. Subsequently, sections were incubated with the LDHA antibody (1:400) at room temperature for $40 \mathrm{~min}$ and with the secondary antibody (cat. no. GK500710; Dako) at room temperature for $30 \mathrm{~min}$. Non-immune normal IgG serum (cat. no. BMR371; Beijing Bersee Technology Co., Ltd.) was used as the control, and the control staining was performed at the same dilution. Staining was developed by diaminobenzidine (cat. no. GK500710; Dako) at room temperature in the dark for $5 \mathrm{~min}$ and cell nuclei were stained with hematoxylin (cat. no. G1140; Beijing Solarbio Science \& Technology Co., Ltd.) at room temperature for $60 \mathrm{sec}$. H-scores of staining results were calculated using the equation: $\mathrm{H}-\mathrm{Score}=\sum \mathrm{Pi}(\mathrm{i}+1)$, where i refers to the intensity of staining (1, weak; 2 , moderate; or 3 , strong) and Pi represents the positive rate of stained cells, with intensities ranging from $0-100 \%$. LDHA expression was classified into two groups: Low expression group when $\mathrm{H}$-Score was $<1$ or the high expression group when $\mathrm{H}$-Score was $\geq 1$. H-score data were analyzed using Kruskal-Wallis test with Bonferroni post hoc test.

Western blotting. Western blotting was carried out according to standard experimental procedures. ImageJ $1.52 \mathrm{a}$ (National Institutes of Health) analysis was applied to determine the signal intensity of immunoblotted target proteins. Antibodies used in the study are listed in Table SI.

Reverse transcription-quantitative PCR (RT-qPCR). Total RNA from treated cells was extracted using TRIzol ${ }^{\circledR}$ reagent (Invitrogen; Thermo Fisher Scientific, Inc.). Total RNA $(1 \mu \mathrm{g})$ was reverse transcribed into cDNA using reverse transcriptase (M-MLV; Promega Corporation), dNTP (Promega Corporation) and Oligo(dT)15 (Promega Corporation). RT was conducted at $42^{\circ} \mathrm{C}$ for $1 \mathrm{~h}$, according to the reverse transcriptase manufacturer's instructions. RT-qPCR was performed with FastStart Universal SYBR ${ }^{\circledR}$ Green Master (Roche Diagnostics) and a CFX96 real-time quantitative system (Bio-Rad Laboratories, Inc.). qPCR was performed according to the SYBR ${ }^{\circledR}$ Green Master manufacturer's instructions: $95^{\circ} \mathrm{C}$ for $3 \mathrm{~min}$, followed by 40 cycles at $95^{\circ} \mathrm{C}$ for $15 \mathrm{sec}, 60^{\circ} \mathrm{C}$ for $30 \mathrm{sec}$ and $72^{\circ} \mathrm{C}$ for $30 \mathrm{sec}$, and a final cycle at $95^{\circ} \mathrm{C}$ for $15 \mathrm{sec}, 60^{\circ} \mathrm{C}$ for $60 \mathrm{sec}$ and $95^{\circ} \mathrm{C}$ for $15 \mathrm{sec}$. $18 \mathrm{~S}$ was used as the internal control, and expression values were normalized to the mean value of $18 \mathrm{~S}$ rRNA. Quantification of mRNA abundance was based on the threshold cycle $(\mathrm{Cq})$ as $2^{-\Delta(\Delta \mathrm{Cq})}$, where $\Delta \mathrm{Cq}=\mathrm{Cq}(\mathrm{LDHA})-\mathrm{Cq}(18 \mathrm{~S})$ and $\Delta(\Delta \mathrm{Cq})=\mathrm{Cq}($ experimental group) - $\mathrm{Cq}$ (control group) (30). Primer sequences are listed in Table SII.

LDHA interference. The infection efficiency and knockdown rate of primary cultured cells were both too low; therefore, the following experiments were conducted in immortalized THESC cells (American Type Culture Collection; cat. no. 4003TM) and Ishikawa cells (cat. no. BNCC 338693; BeNa Culture Collection; Beijing Beina Chunglian Institute of Biotechnology). Both of these cell lines are model cell lines of the endometrium $(31,32)$. Lentivirus LDHA interference sequence [short hairpin (sh-)LDHA in a GV248 lentiviral plasmid; Shanghai GeneChem Co., Ltd] with the target sequence 5'-GGCAAAGACTATAATGTAA-3' (vehicle components: hU6-MCS-Ubiquitin-EGFP-IRES-puromycin) and the non-targeting negative control (sh-Con) were infected into Ishikawa cells and THESC cells with a MOI of 10. After infection for $12 \mathrm{~h}$ at $37^{\circ} \mathrm{C}$, the culture medium was replaced with complete medium. After $72 \mathrm{~h}$, proteins were harvested, and western blotting was applied to assess the effect of infection.

Apoptosis analysis. LDHA-silenced Ishikawa cells, THESC cells and their counterpart controls were inoculated into $6-\mathrm{cm}$ dishes at a density of $3 \times 10^{5}$ cells/dish. Subsequently, $12 \mathrm{~h}$ after adhesion, cells were cultured under normoxia $\left(21 \% \mathrm{O}_{2}\right)$ or hypoxia $\left(1 \% \mathrm{O}_{2}\right)$ for $24 \mathrm{~h}$. An Annexin V-FITC/propidium iodide (PI) apoptosis assay kit (cat. no. AD10; Dojindo Molecular Technologies, Inc.) was used to detect apoptotic cells. Trypsinized cells were washed twice with PBS and suspended in $100 \mu \mathrm{l} 1 \mathrm{X}$ Annexin V binding solution. Subsequently, $5 \mu \mathrm{l}$ each of Annexin V-FITC and PI staining solutions were added to the cell suspension, which was incubated at room temperature in the dark for $15 \mathrm{~min}$. After adding $400 \mu 1$ 1X Annexin V binding solution, apoptosis was detected using flow cytometry (CytoFLEX; Beckman Coulter, Inc.) and analyzed with CytExpert for DxFLEX (2.0.0.274; Beckman Coulter, Inc.). The apoptotic cell rate (\%) was calculated as Annexin V-positive cells/the total number of cells. 
Cell cycle analysis. LDHA-silenced Ishikawa cells, THESC cells and their counterpart controls were exposed to normoxia or hypoxia for $24 \mathrm{~h}$. Subsequently, cells were collected and fixed overnight with $70 \%$ ethanol at $4^{\circ} \mathrm{C}$. After removing the fixative solution by centrifugation at $200 \mathrm{x}$ g for $5 \mathrm{~min}$ at room temperature, cell pellets were washed twice with ice-cold PBS, and treated with RNase A (10 $\mu \mathrm{g} / \mathrm{ml}$; cat. no. ST579; Beyotime Institute of Biotechnology) and PI (final concentration, $50 \mu \mathrm{g} / \mathrm{ml}$ ) at room temperature in the dark for $30 \mathrm{~min}$. PI-stained cells were evaluated by flow cytometry (CytoFLEX; Beckman Coulter, Inc.) for cell cycle phase distribution within $1 \mathrm{~h}$. Cell phase distribution was analyzed with FlowJo v10 (Flowjo, LLC).

Detection of cellular ATP levels. LDHA-silenced Ishikawa cells, THESC cells and their counterpart controls were exposed to normoxia or hypoxia for $24 \mathrm{~h}$. ATP levels in GC lysates were measured using a luminometer (Synergy H4; BioTek Instruments, Inc.) according to the manufacturer's instructions of the ATP kit (cat. no. S0027; Beyotime Institute of Biotechnology).

Analysis of mitochondrial membrane potential (MMP). MMP was determined by flow cytometry using the JC-1 assay kit (cat. no. C2006; Beyotime Institute of Biotechnology). LDHA-silenced Ishikawa cells, THESC cells and their counterpart controls were exposed to normoxia or hypoxia for $24 \mathrm{~h}$. The collected cells were treated according to the manufacturer's instructions. Each sample was assessed by flow cytometry (CytoFLEX; Beckman Coulter, Inc.) for red (JC-1 aggregates) and green (JC-1 monomers) fluorescence and analyzed with CytExpert for DxFLEX (2.0.0.274; Beckman Coulter, Inc.). Relative MMP ratio was calculated as red fluorescence intensity/green fluorescence intensity. The relative signal intensities of JC-1 aggregates and monomers were normalized to the control group.

Analysis of reactive oxygen species (ROS). ROS content was determined by flow cytometry using a ROS assay kit (cat. no. S0033; Beyotime Institute of Biotechnology). LDHA-silenced Ishikawa cells, THESC cells and their counterpart controls, were exposed to normoxia or hypoxia for $24 \mathrm{~h}$. The collected LDHA-silenced and sh-Con cells were incubated with $10 \mu \mathrm{M}$ 2'-7'dichlorofluorescin diacetate (DCFH-DA) dye (cat. no. S0033; Beyotime Institute of Biotechnology) for $20 \mathrm{~min}$ at $37^{\circ} \mathrm{C}$. Each sample was assessed by flow cytometry (CytoFLEX; Beckman Coulter, Inc.) for fluorescence intensity. Data were analyzed with CytExpert for DxFLEX (2.0.0.274; Beckman Coulter, Inc.).

Cell Counting Kit-8 (CCK-8) assay. LDHA-silenced Ishikawa cells and THESC cells and their counterpart controls were grown to logarithmic phase, trypsinized, counted and inoculated into 96-well plates at a density of $2 \times 10^{3}$ cells/well. Cell proliferation rates were measured for 7 days using the CCK- 8 assay (cat. no. CK04; Dojindo Molecular Technologies, Inc.). CCK-8 reagent $(10 \mu \mathrm{l})$ was added to $100 \mu \mathrm{l}$ DMEM/F12 with $10 \%$ FBS, and was added to cells in a humidified atmosphere containing $5 \% \mathrm{CO}_{2}$ at $37^{\circ} \mathrm{C}$ for $1 \mathrm{~h}$ and absorbance was measured at $450 \mathrm{~nm}$ at the same time each day, according to the manufacturer instructions.
Transwell migration assay. LDHA-silenced Ishikawa cells, THESC cells and their counterpart controls were trypsinized and resuspended in serum-free medium. Cell suspensions containing $2 \times 10^{4}$ cells in a $200-\mu l$ volume were added to the upper chamber of each Transwell $(8.0-\mu \mathrm{m}$ aperture; Corning, Inc.), whereas $700 \mu 1$ complete culture medium supplemented with $10 \%$ FBS was added to the lower chamber. Ishikawa cells were cultured for $48 \mathrm{~h}$, whereas THESC cells were cultured for $24 \mathrm{~h}$. Cells in the upper chamber were fixed in $75 \%$ alcohol for $20 \mathrm{~min}$ at room temperature and stained with crystal violet for $5 \mathrm{~min}$ at room temperature. Subsequently, cells remaining in the upper chamber were wiped off, and cells that migrated through the membrane were counted under a light microscope.

Lactic acid detection. LDHA-silenced Ishikawa cells, THESC cells and their counterpart controls were cultured for $24 \mathrm{~h}$, trypsinized and counted. The lactic acid concentration in the collected medium was determined with a blood gas analyzer (Cobas B 221; Roche Diagnostics). Lactate production is presented as the amount of lactate normalized to cell number.

Statistical analysis. The experiments were performed in triplicate and repeated three times. Data are expressed as the mean \pm standard deviation. SPSS version 25.0 (IBM Corp.) and GraphPad Prism version 7 (GraphPad Software, Inc.) were used for statistical analysis. Student's t-test was used for comparison of two groups of data and one-way or two-way ANOVA was used for comparison of multiple groups of data, followed by the Bonferroni correction. Fisher's exact test was used to analyze normal endometrium and eutopic endometrium groups, and $\chi^{2}$ test was used to analyze ectopic endometrium groups. H-score data were analyzed using Kruskal-Wallis test with Bonferroni post hoc test. Differences in the expression levels of LDHA (based on H-Score) in paired eutopic and ectopic tissues obtained from 25 patients with endometriosis were analyzed using Wilcoxon signed-rank test. $\mathrm{P}<0.05$ was considered to indicate a statistically significant difference.

\section{Results}

LDHA expression is increased in endometriotic lesions. The results from immunohistochemical analysis of normal endometrium showed that LDHA protein was expressed in both endometrial glandular cells and stromal cells, and was mainly located in the cytoplasm (Fig. 1A). In the independent samples, the LDHA protein expression levels in ectopic endometrium were significantly increased compared with those in normal and eutopic endometria, with no significant difference in LDHA expression observed between the latter two groups (Fig. 1A and B). The protein expression levels of LDHA in ectopic endometrial glandular cells and stromal cells were significantly higher than in paired eutopic endometrial in 25 patients with endometriosis (Table SIII). Additionally, the LDHA protein expression levels in ectopic endometrial glandular cells were significantly higher during the proliferative phase compared with during the secretive phase (Table II). However, no difference in LDHA protein expression levels was observed in ectopic endometrial stromal cells (EcESCs) at different endometrial growth cycles (Table II). 
A
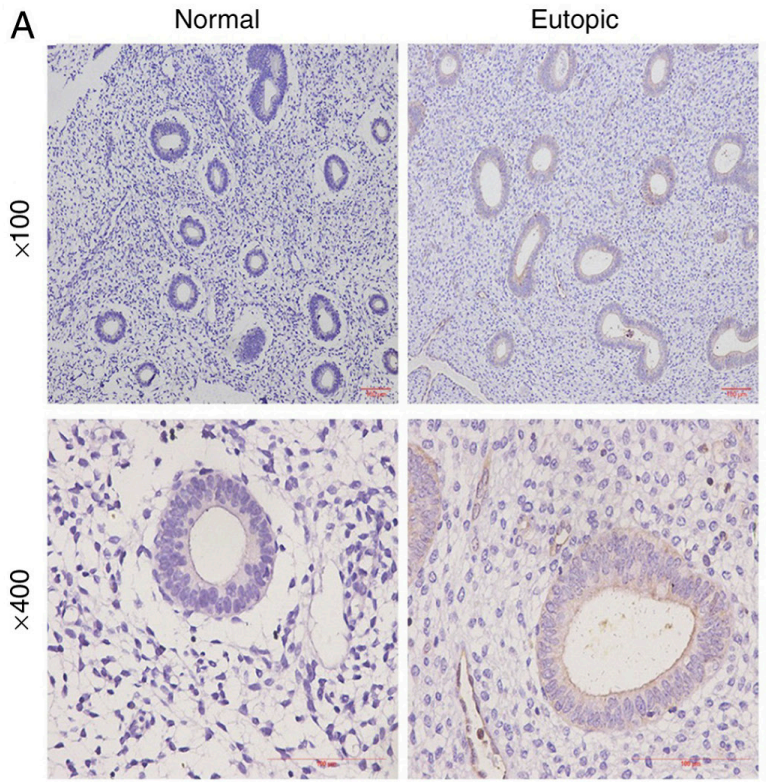

B

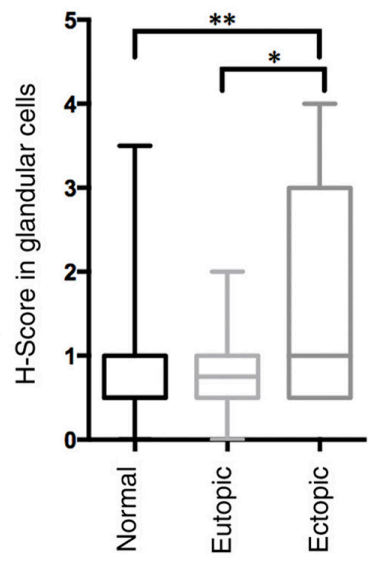

Eutopic

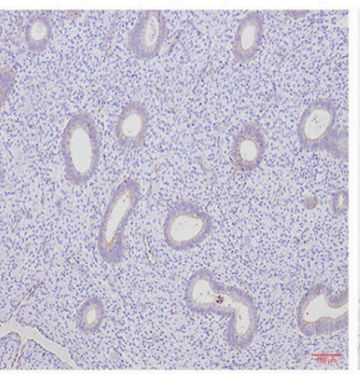

$\lg G$
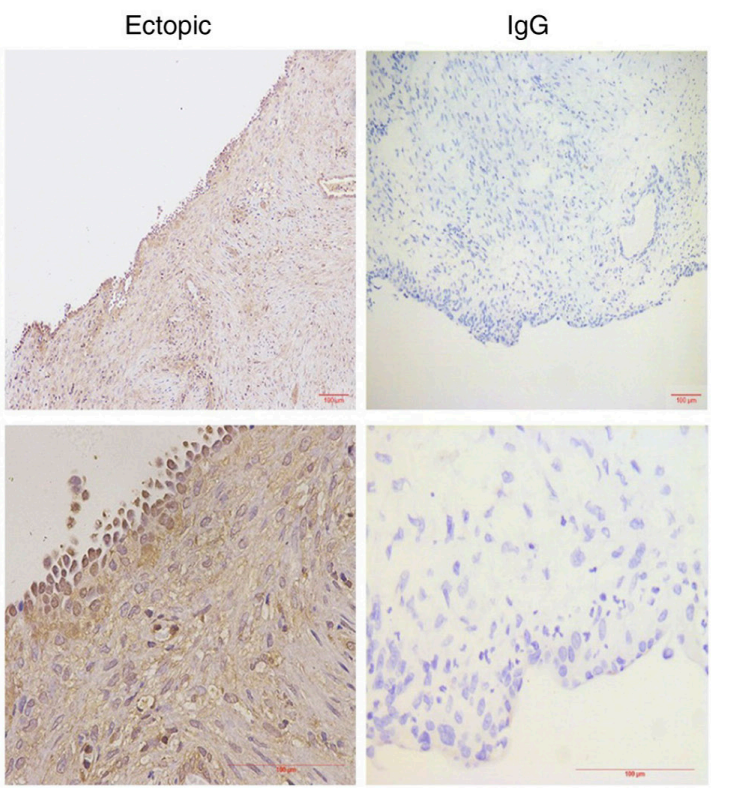

C

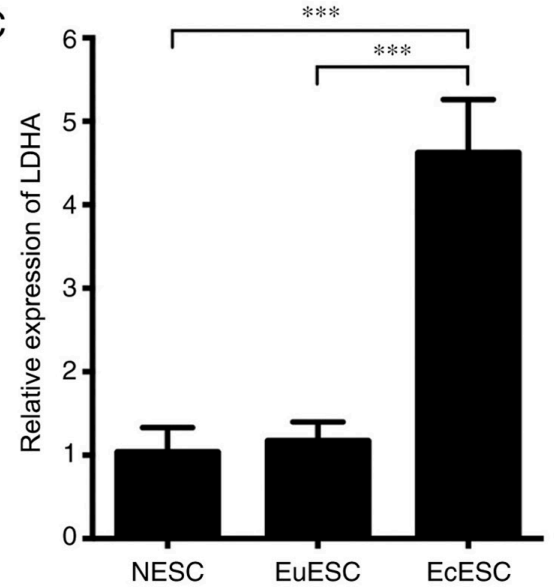

D
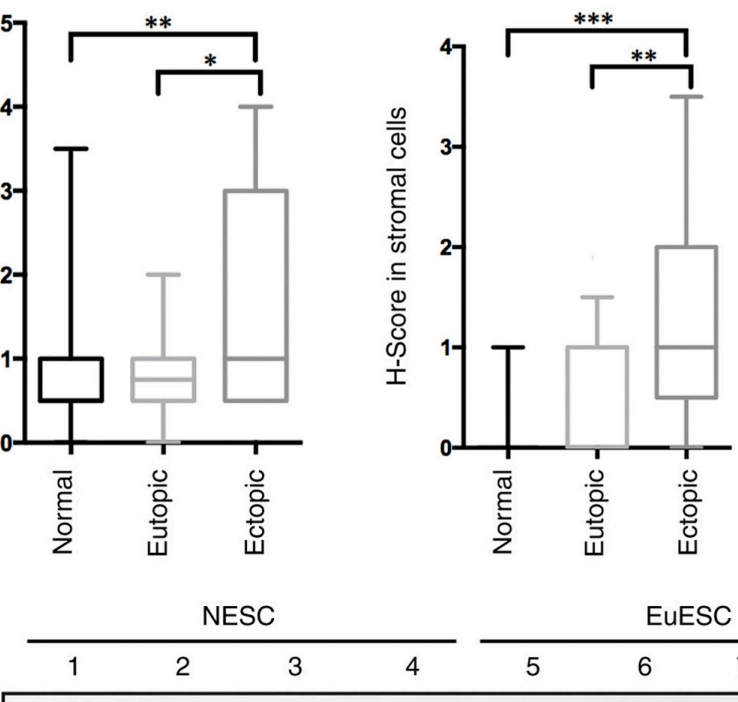
\begin{tabular}{ll} 
& EuESC \\
\hline 5 & 6
\end{tabular}
6

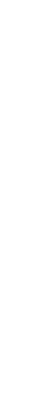


Table II. Lactate dehydrogenase A expression in glandular and stromal cells during menstrual phases.

\begin{tabular}{|c|c|c|c|c|c|c|}
\hline \multirow[b]{2}{*}{ Sample type } & \multicolumn{2}{|c|}{ Glandular cells } & \multirow[b]{2}{*}{$\mathrm{P}$-value } & \multicolumn{2}{|c|}{ Stromal cells } & \multirow[b]{2}{*}{ P-value } \\
\hline & Low & High & & Low & High & \\
\hline Normal endometrium $^{\mathrm{a}}$ & & & 0.366 & & & 0.715 \\
\hline Proliferative phase & 13 & 10 & & 21 & 2 & \\
\hline Secretive phase & 9 & 3 & & 12 & 0 & \\
\hline Eutopic endometrium ${ }^{\mathrm{a}}$ & & & 0.602 & & & 0.099 \\
\hline Proliferative phase & 12 & 17 & & 21 & 8 & \\
\hline Secretive phase & 7 & 3 & & 10 & 0 & \\
\hline Ectopic endometrium ${ }^{\mathrm{b}}$ & & & 0.03 & & & 0.355 \\
\hline Proliferative phase & 7 & 32 & & 14 & 25 & \\
\hline Secretive phase & 10 & 13 & & 11 & 12 & \\
\hline
\end{tabular}

${ }^{a}$ Fisher's exact test. ${ }^{b} \chi$-square test.

expression in tumor cells (33). The current study investigated whether hypoxia influenced LDHA expression in ESCs and in immortalized endometrial glandular cells using the Ishikawa cell line. RT-qPCR showed that both HIF-1 $\alpha$ and LDHA mRNA expression levels were increased in ESCs (including NESCs, EuESCs and EcESCs) and in Ishikawa cells after exposure to hypoxia, with the mRNA expression levels of these proteins significantly increasing with the prolongation of hypoxia (Fig. S2).

Western blotting results also showed that HIF-1 $\alpha$ increased significantly within a short time (4 h) in ESCs and Ishikawa cells exposed to hypoxia, and remained high for 24 or even $48 \mathrm{~h}$. However, the changes in LDHA expression lagged behind the increase in HIF-1 $\alpha$ expression. A significant difference in LDHA expression was shown after $4 \mathrm{~h}$ of hypoxia and continued for $48 \mathrm{~h}$ (Fig. 2A-D). Additionally, the HIF-1 $\alpha$ and LDHA expression levels in EcESCs without hypoxia were significantly increased compared with NESCs and EuESCs. Notably, LDHA protein expression levels in EcESCs remained higher compared with those in NESCs and EuESCs after hypoxia treatment for 12 or $48 \mathrm{~h}$ (Fig. 2E).

LDHA-knockdown increases apoptosis of Ishikawa cells and THESC cells. To examine the function of LDHA in endometrial glandular epithelial and mesenchymal cells, Ishikawa cells and THESC cells were infected with a sh-LDHA lentivirus. Compared with control virus-infected cells (sh-Con), LDHA protein expression levels in sh-LDHA virus-infected Ishikawa cells and THESC cells were reduced (Figs. 3C and 4C). Flow cytometry was conducted to examine the effect of LDHA-knockdown on apoptosis. The results showed that LDHA-knockdown significantly increased the rate of apoptotic Ishikawa cells (Fig. 3A and B). Western blotting showed that the expression levels of proapoptotic proteins, including BID, BAX, BIK, BIM, PUMA, phosphorylated (P)-BAD/BAD and cleaved $(C)$-caspase 3 , were significantly increased after LDHA-knockdown (Fig. 3C and D). Consistent with these results, LDHA-knockdown significantly increased apoptosis of THESC cells compared with that in the control cells (Fig. 4A and B). Moreover, BID, BAX, BIK, $\mathrm{P}-\mathrm{BAD} / \mathrm{BAD}$ and $\mathrm{C}$-caspase 3 protein expression levels in the LDHA-knockdown groups were significantly upregulated compared with those in the control group (Fig. 4C and D).

Effect of LDHA-knockdown on mitochondrial function in Ishikawa cells and THESC cells. Mitochondria are the key energy-producing organelles and cellular source of ROS, which are responsible for managing cell life and death by controlling cell respiration and ATP synthesis (34). Changes in MMP caused by hypoxia can lead to mitochondrial permeability transition and the release of mitochondrial pro-apoptotic factors, resulting in apoptosis (35).

The present study investigated mitochondrial functions in LDHA-silenced cells under hypoxic or normoxic conditions. Hypoxia led to suppressed ATP production, decreased MMP levels and increased ROS levels in THESC cells (Fig. 5B, $\mathrm{D}$ and $\mathrm{F}$ ), whereas no significant difference was found in Ishikawa cells. Under both normoxic and hypoxic conditions, knockdown of LDHA in Ishikawa cells and THESC cells significantly reduced ATP and MMP levels, and induced increased aggregation of ROS (Fig. 5A-F).

Effects of LDHA-knockdown on cell cycle distribution of Ishikawa cells and THESC cells. To examine the effect of LDHA-knockdown on the cell cycle, LDHA-silenced Ishikawa cells and THESC cells were analyzed by flow cytometry after PI staining. The results showed that compared with the control group, LDHA interference significantly increased the proportion of $\mathrm{G}_{1}$-phase Ishikawa cells and decreased that of S-phase cells (Fig. S3A and C). However, LDHA-knockdown did not affect the cell cycle distribution of THESC cells (Fig. S3B and D). Consistently, western blotting results showed that $\mathrm{p} 21$ expression levels were increased in the Ishikawa knockdown group compared with the control group (Fig. S3E), whereas no change in p21 expression was observed in THESC cells (Fig. S3F). 
A

NESC
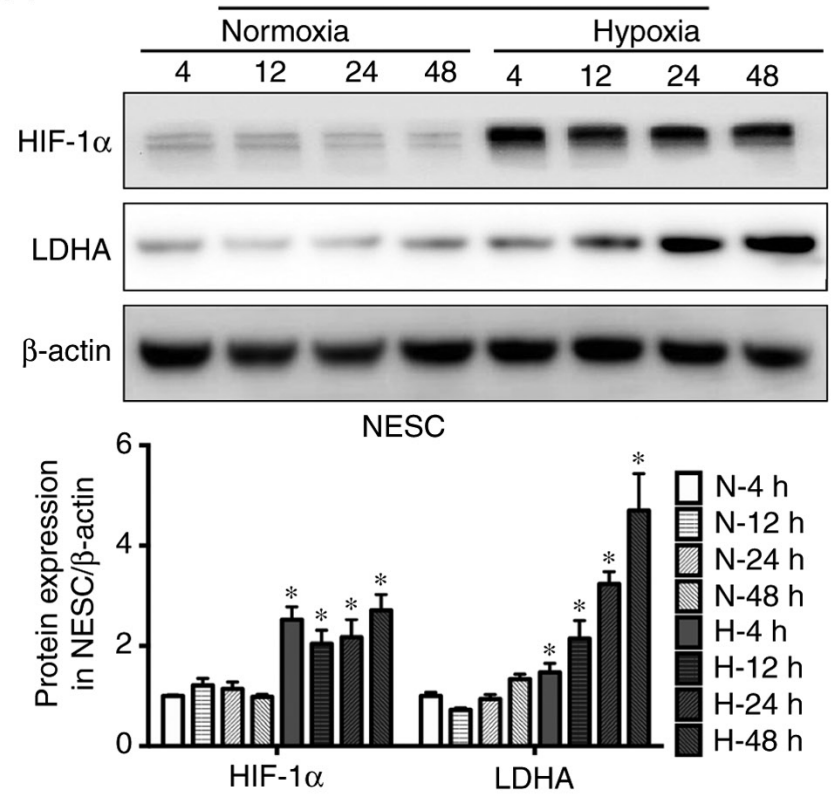

C

\begin{tabular}{|c|c|c|c|c|c|}
\hline \multicolumn{6}{|c|}{ EcESC } \\
\hline & Normoxia & & & & xia \\
\hline 4 & 12 & 48 & 4 & 12 & 24 \\
\hline
\end{tabular}

HIF-1 $\alpha$

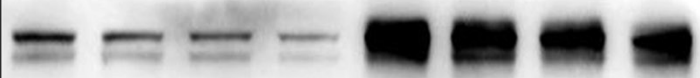

LDHA

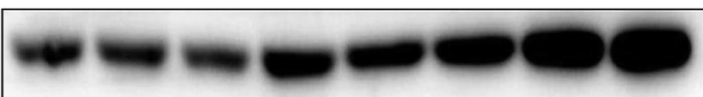

$\beta$-actin
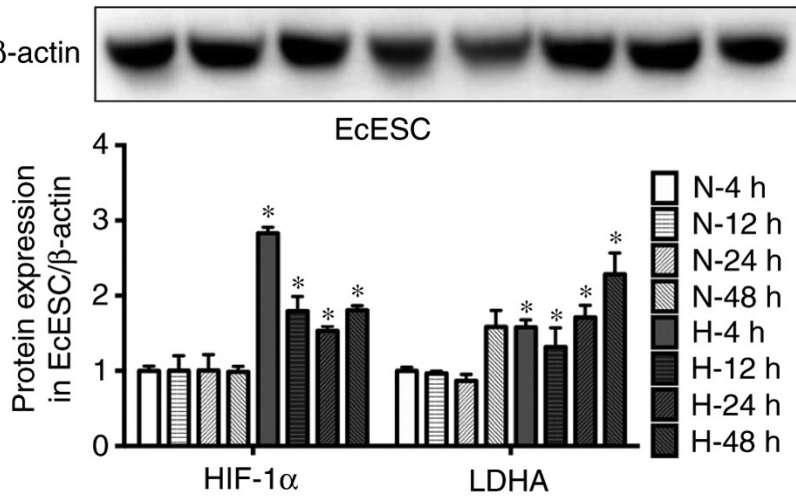

E

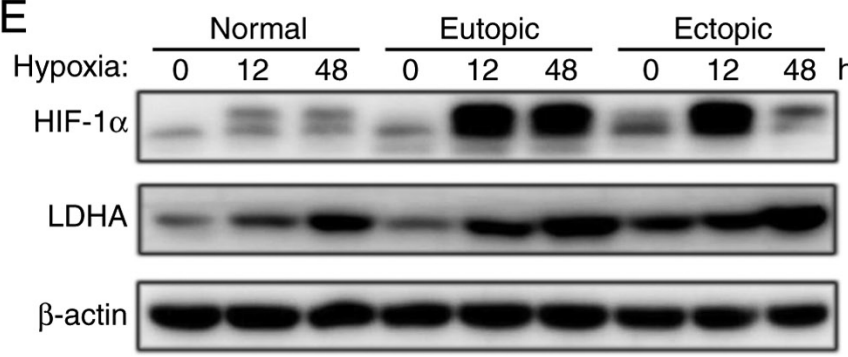

B
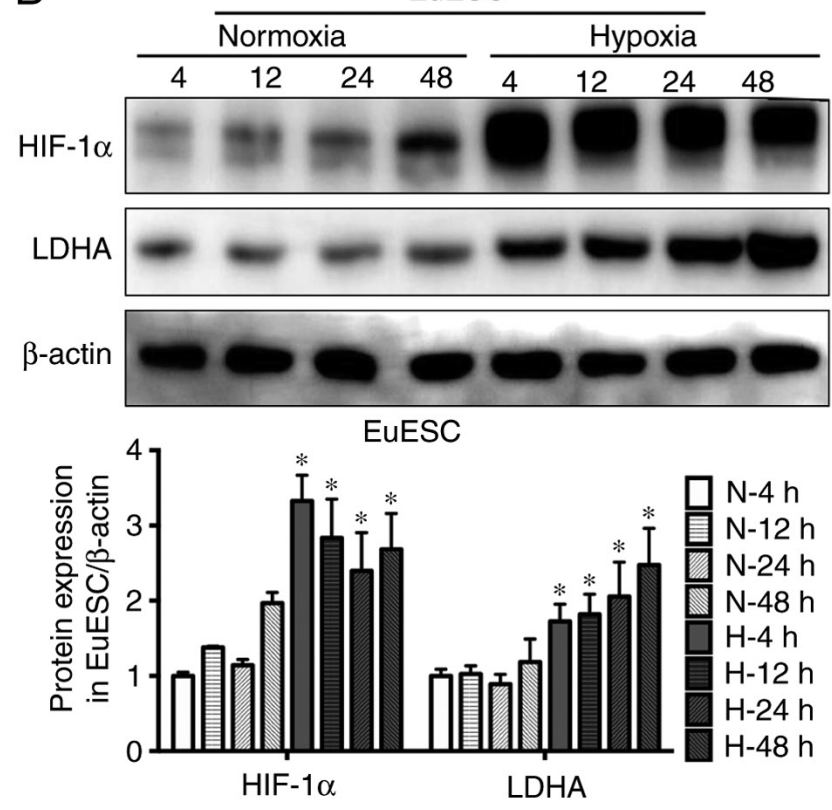

D

Ishikawa
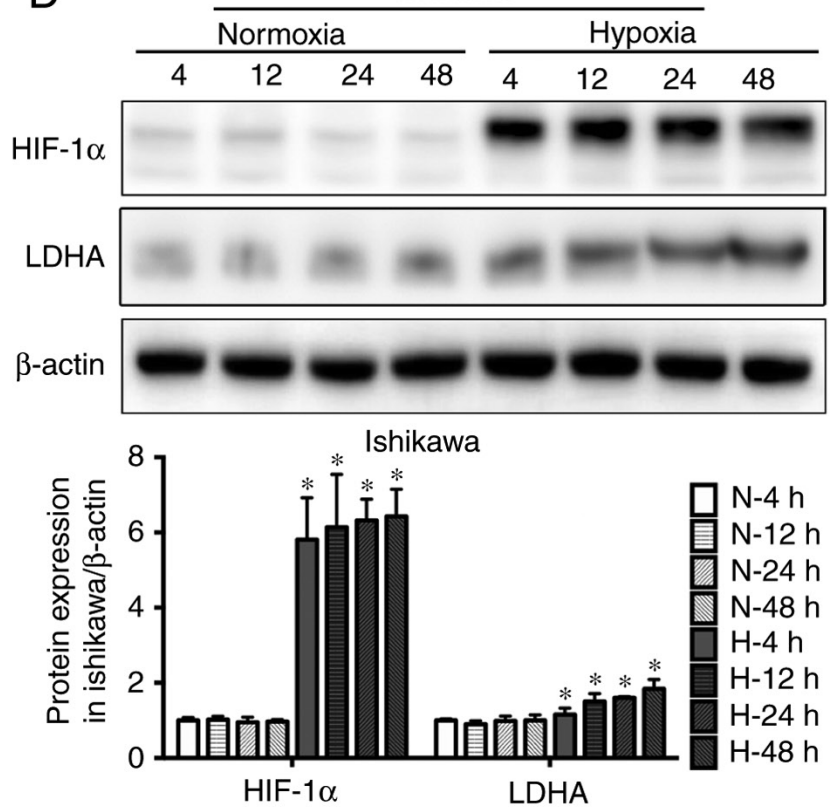

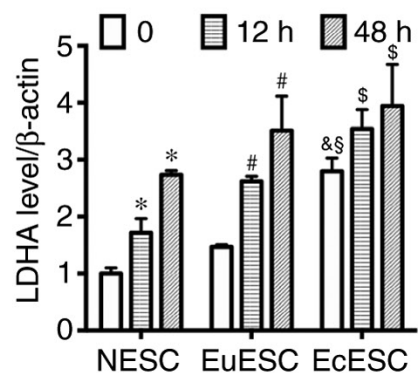

Figure 2. Hypoxia induces LDHA expression in endometrial cells. Western blot analysis of HIF-1 $\alpha$ and LDHA expression in (A) NESCs, (B) EuESCs, (C) EcESCs and (D) Ishikawa cells at 4, 12, 24 and $48 \mathrm{~h}$ after culture in normoxic or hypoxic conditions. Upper panel shows protein bands, whereas the lower panel shows a histogram semi-quantifying the results of corresponding treatments. One-way ANOVA and Bonferroni post hoc test were used to analyze multiple comparisons. "P $<0.05$, hypoxia vs. normoxia group at the same time point. (E) Western blot analysis of HIF-1 $\alpha$ and LDHA expression in NESCs, EuESCs and EcESCs after 12 or $48 \mathrm{~h}$ of normoxia or hypoxia. The left panel shows protein bands, the middle panel shows a histogram of HIF-1 $\alpha$ expression in the three cell types, and the right panel shows a histogram of LDHA expression. $\beta$-actin was used as a loading control. Values are expressed as mean \pm SD of three independent experiments. Two-way ANOVA and Bonferroni post hoc test were used to analyze multiple comparisons. " $\mathrm{P}<0.05$, hypoxia vs. normoxia group in NESCs; ${ }^{\#} \mathrm{P}<0.05$, hypoxia vs. normoxia group in EuESCs; ${ }^{\$} \mathrm{P}<0.05$, hypoxia vs. normoxia group in EcESCs; ${ }^{\circledR} \mathrm{P}<0.05$, EcESCs vs. NESCs in normoxia; ${ }^{\S} \mathrm{P}<0.05$, EcESCs vs. EuESCs in normoxia. LDHA, lactate dehydrogenase A; HIF-1 $\alpha$, hypoxia inducible factor 1 $\alpha$; NESC, normal endometrial stromal cells; EuESC, eutopic endometrial stromal cells; EuESC, eutopic endometrial stromal cells. 
A
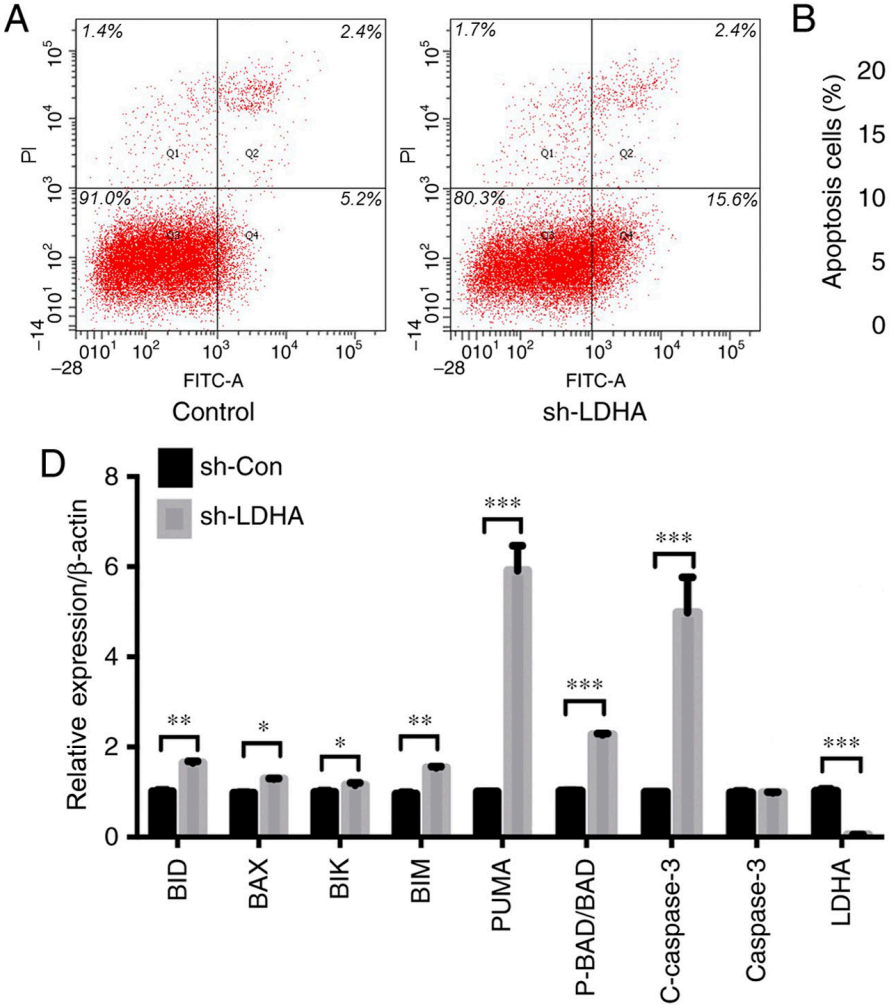

$\mathrm{B}$
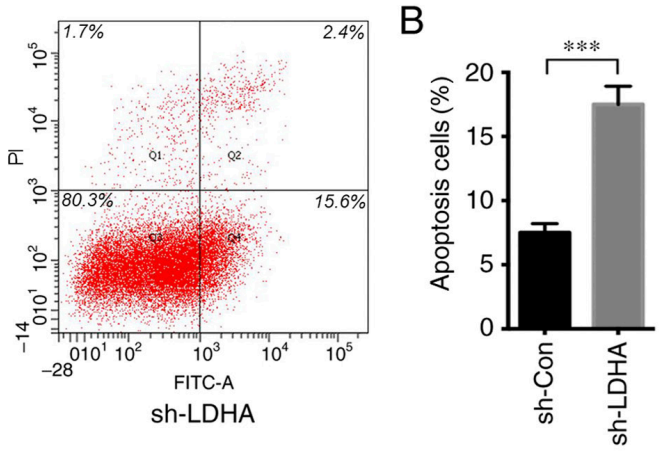

C

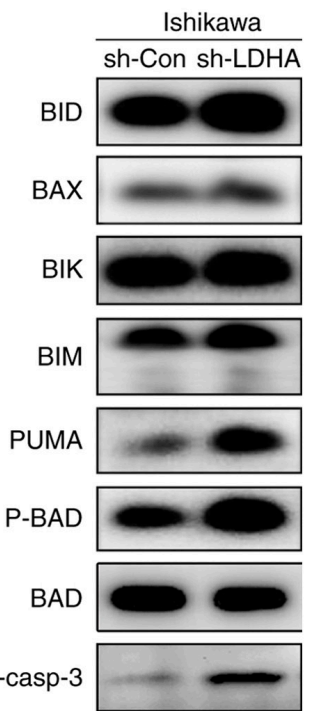

Caspase-3

LDHA

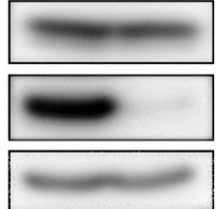

Figure 3. Effect of LDHA on apoptosis of Ishikawa cells. (A) Representative graphs of apoptosis detected by flow cytometry. (B) A higher number of Ishikawa cells underwent apoptosis when LDHA was knocked down (sh-LDHA) compared with the control (sh-Con). (C) Western blot analysis of apoptosis-related proteins. (D) Histogram of BID, BAX, BIK, BIM, PUMA, P-BAD/BAD, C-caspase 3, total caspase 3 and LDHA protein expression in Ishikawa cells. Values are expressed as mean $\pm \mathrm{SD}$ of three independent experiments. Student's t-test was used to compare two groups. ${ }^{*} \mathrm{P}<0.05,{ }^{* * *} \mathrm{P}<0.01$ and ${ }^{* * * *} \mathrm{P}<0.001$. LDHA, lactate dehydrogenase A; C-, cleaved; sh-, short hairpin; Con-, control; P-, phosphorylated.

A
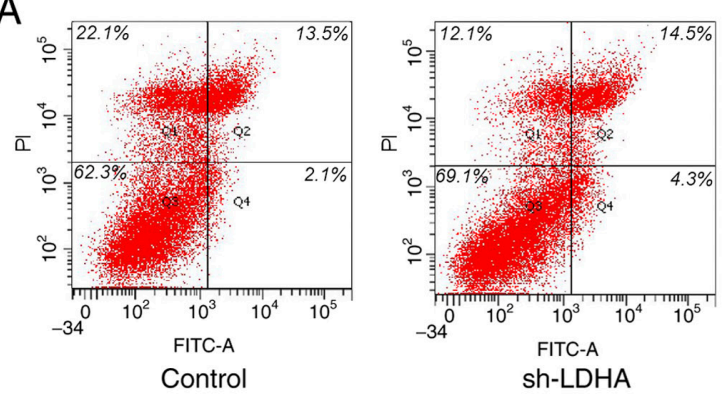

D

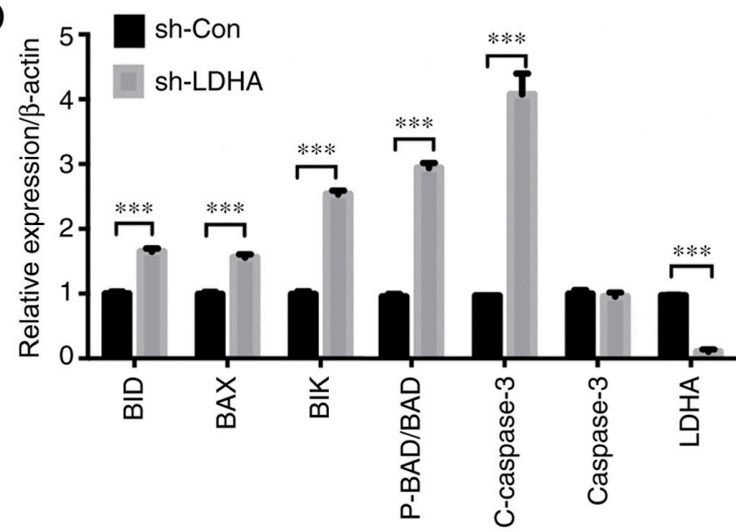

$\mathrm{B}$

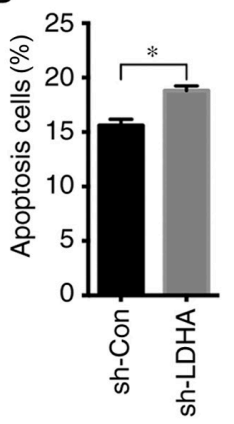

C

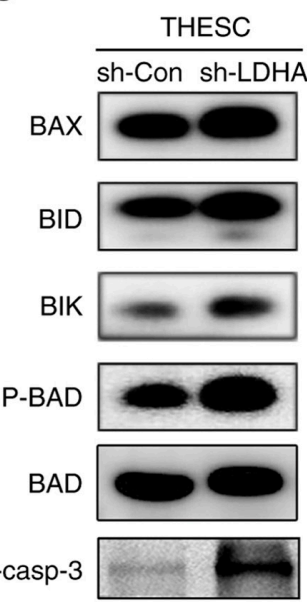

Caspase-3

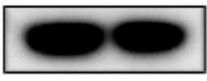

LDHA

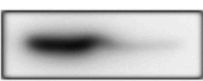

$\beta$-actin

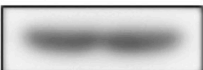

Figure 4. Effect of LDHA on apoptosis of immortalized human endometrial stromal cells (THESC cells). (A) Representative graphs of apoptosis detected by flow cytometry. (B) An increased number of THESC cells underwent apoptosis when LDHA was knocked down (sh-LDHA) compared with the control (sh-Con). (C) Western blot analysis of apoptosis-related proteins. (D) Histogram of BID, BAX, BIK, P-BAD/BAD, C-caspase 3, total caspase 3 and LDHA protein expression in THESC cells. Values are expressed as mean \pm SD of three independent experiments. Student's t-test was used to compare two groups. ${ }^{*} \mathrm{P}<0.05$ and $^{* * * *} \mathrm{P}<0.001$. LDHA, lactate dehydrogenase A; sh-, short hairpin; Con-, control; C-, cleaved; P-, phosphorylated. 
A

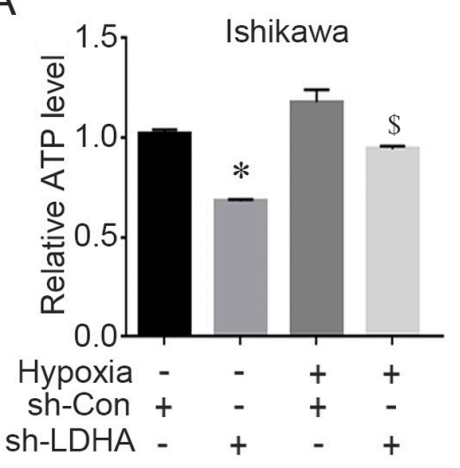

B

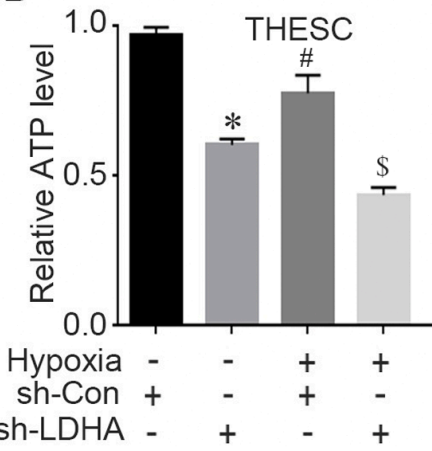

C
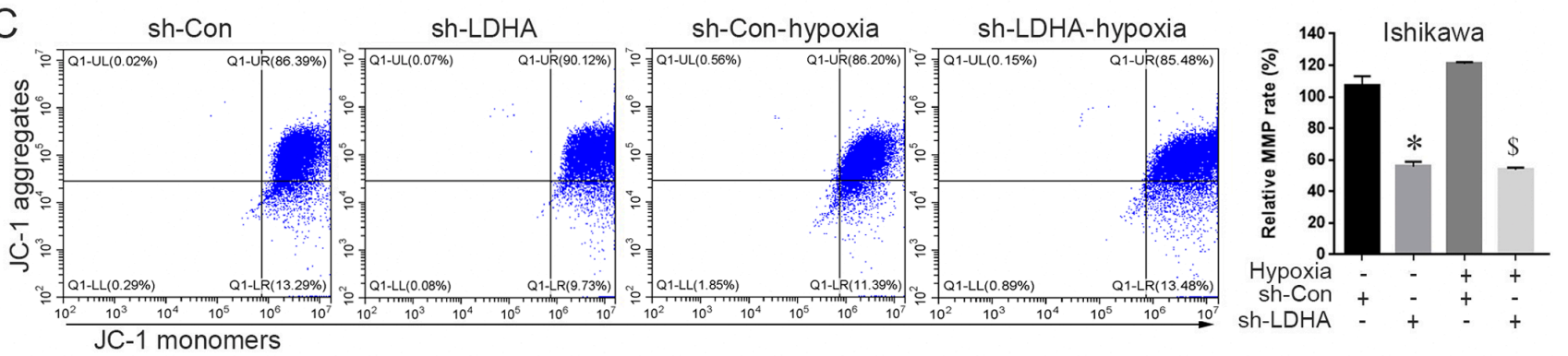

$\mathrm{D}$
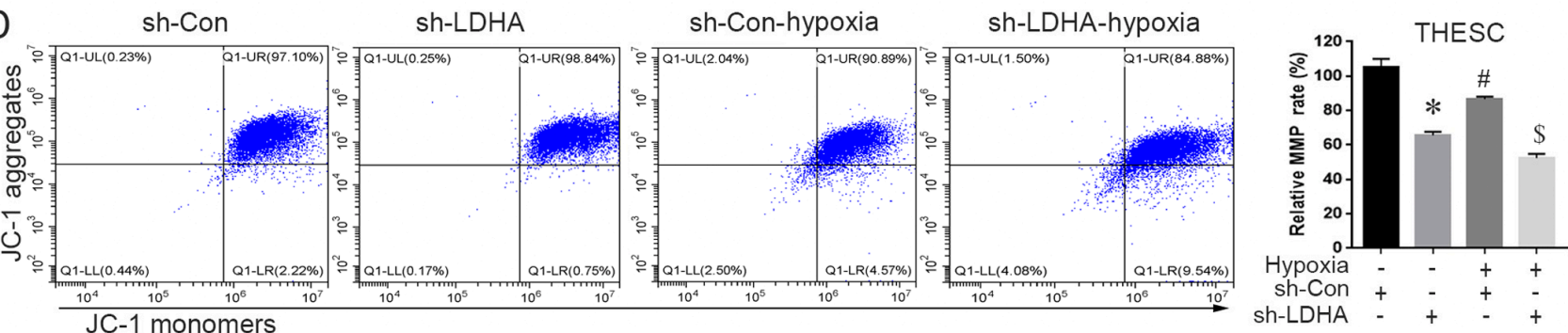

$\mathrm{E}$
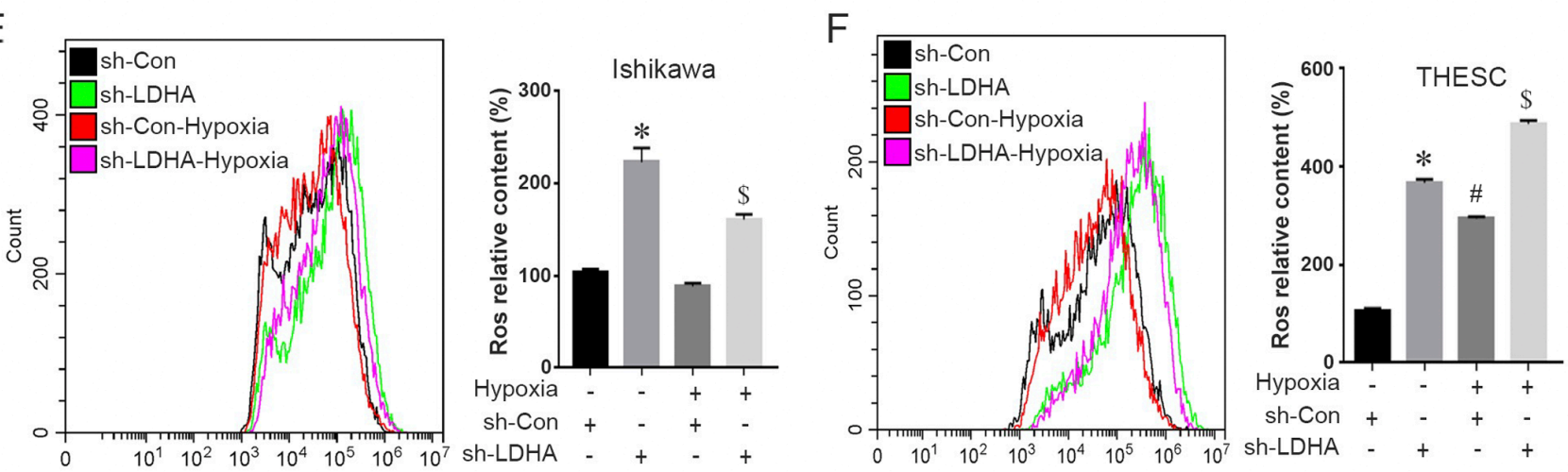

Figure 5. Effect of LDHA-knockdown on mitochondrial function of Ishikawa cells and THESC cells. Intracellular ATP levels in (A) Ishikawa cells and (B) THESC cells after $24 \mathrm{~h}$ of culture under normoxic or hypoxic conditions. The MMP ratio was measured by flow cytometry in (C) Ishikawa cells and (D) THESC cells. The left panels show representative graphs of MMP values detected by flow cytometry and the right panels show a histogram of the MMP ratio. Intracellular ROS levels in different treatment groups of (E) Ishikawa cells and (F) THESC cells were determined by 2'-7'dichlorofluorescin diacetate fluorescence. The left panels show representative graphs of intracellular ROS levels detected by flow cytometry and the right panels show a histogram of the ROS relative content. Values are expressed as mean \pm SD of three independent experiments. Two-way ANOVA and Bonferroni post hoc test were used to analyze multiple comparisons. " $\mathrm{P}<0.05$, sh-LDHA vs. sh-Con in normoxia; ${ }^{~} \mathrm{P}<0.05$, normoxia vs. hypoxia in sh-Con group; ${ }^{\$} \mathrm{P}<0.05$, sh-LDHA vs. sh-Con in hypoxia. LDHA, lactate dehydrogenase A; MMP, mitochondrial membrane potential; ROS, reactive oxygen species; sh-, short hairpin; Con, control.

Effects of LDHA-knockdown on migration and proliferation of Ishikawa cells and THESC cells. The results of the Transwell assay showed that the numbers of migrated Ishikawa cells and THESC cells in the LDHA-knockdown group were significantly decreased compared with those in the control groups (Fig. S4A-C). Furthermore, western blotting showed that the expression levels of the epithelial marker E-cadherin in Ishikawa cells were increased when LDHA was knocked down, whereas the mesenchymal marker, $\beta$-catenin, was slightly decreased (Fig. S4D). By contrast, the mesenchymal marker, vimentin, was unchanged in Ishikawa cells (Fig. S4D). Similarly, in LDHA-knockdown THESC cells, $\beta$-catenin expression was decreased, whereas the expression levels of vimentin did not change (Fig. S4D). The CCK-8 assay results 

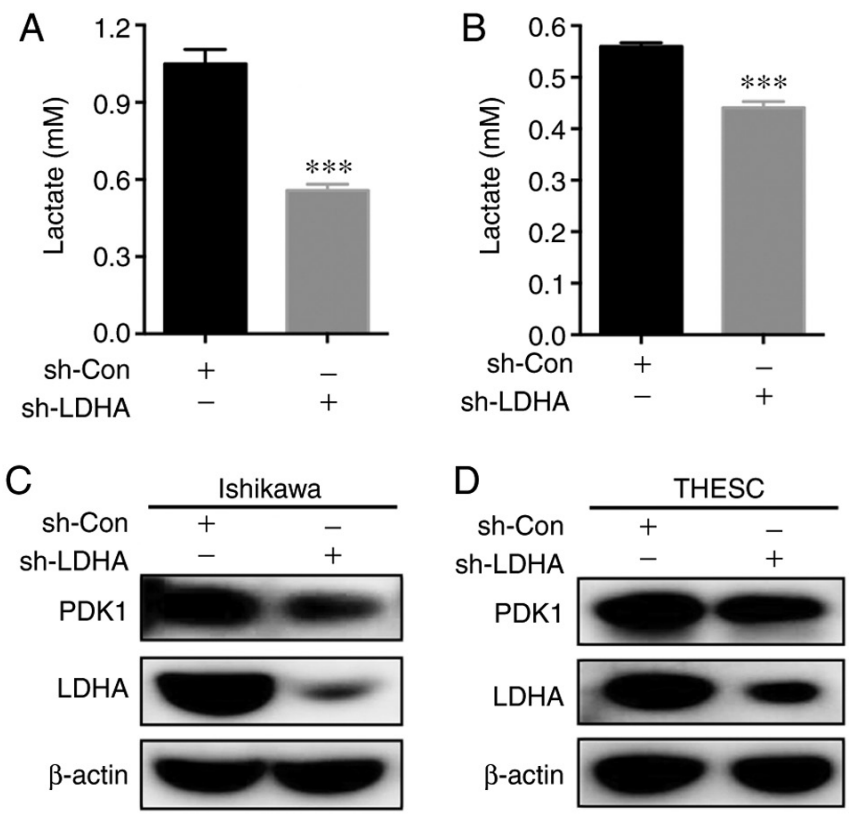

Figure 6. Effect of LDHA-knockdown on metabolism of Ishikawa cells and THESC cells. Histograms showing relative lactate expression in (A) Ishikawa cells and (B) THESC cells. LDHA-knockdown (sh-LDHA) significantly reduced lactate levels compared with their respective control groups (sh-Con). Protein expression levels of PDK1, a key enzyme in glycolysis, were determined by western blotting in (C) Ishikawa cells and (D) THESC cells. $\beta$-actin was used as a loading control. Values are expressed as mean $\pm \mathrm{SD}$ of three independent experiments. Student's t-test was used to compare two groups. ${ }^{* * *} \mathrm{P}<0.001$ vs. sh-Con. LDHA, lactate dehydrogenase A; h-, short hairpin; Con, control; PDK1, pyruvate dehydrogenase kinase 1.

showed no significant changes in the proliferative capacity of Ishikawa cells or THESC cells after LDHA-knockdown (Fig. S4E and F).

LDHA-knockdown impairs the metabolism of Ishikawa cells and THESC cells. LDHA, a key catalytic enzyme for the transformation of pyruvate into lactic acid, is involved in glycolysis regulation (16). To investigate the role of LDHA in endometrial cells, the lactic acid levels in LDHA-knockdown and control cells were measured. The results showed that lactate production in Ishikawa cells and THESC cells was significantly decreased when LDHA was knocked down (Fig. 6A and B). Moreover, western blot analysis of key glycolysis enzymes showed that PDK1 expression was decreased in Ishikawa cells and THESC cells (Fig. 6C and D).

\section{Discussion}

Hypoxia plays critical roles in promoting pathological processes that facilitate the development of endometriosis (36). Moreover, glucose metabolism and energy production in ectopic endometriotic cells under hypoxia have been reported to influence the occurrence and invasion of endometriosis $(36,37)$. LDHA is a key enzyme that catalyzes the conversion of pyruvate into lactic acid for energy metabolism (16). Exploring the expression pattern of LDHA and its potential function in endometriosis may provide critical clues for understanding the regulatory mechanisms of energy production in ectopic endometriotic cells during hypoxia, and may help identify new targets for the treatment of endometriosis.

Previous research has confirmed that HIF-1 $\alpha$ and LDHA expression in ectopic tissues of endometriosis is higher compared with that in normal and eutopic endometrial tissues (9). In the present study, analysis of clinical samples revealed significantly higher LDHA expression levels in ectopic tissues compared with those in normal and eutopic tissues. Additionally, exposure of ESCs and glandular epithelial Ishikawa cells to hypoxia increased LDHA mRNA and protein expression levels. Furthermore, the LDHA expression levels were significantly increased in EcESCs compared with EuESCs and NESCs. These results indicated that hypoxia may play a notable role in the progression of endometriotic cysts in association with upregulated LDHA expression.

Apoptosis is a key cellular process for the development of endometriosis $(38,39)$. Proapoptotic molecules, such as BAD, BID, BIM, BIK, BAX and BAK, induce apoptosis, whereas antiapoptotic molecules, such as BCL-2, BCL-X and BCL-W, inhibit this process (40). Several previous studies reported that patients with endometriosis had a high number of BAX-negative and BCL-2-positive macrophages in their ectopic lesions (41-44). Additionally, the proportion of BCL-2-positive macrophages in the abdominal fluid was significantly increased compared with that in healthy women, which may be associated with the anti-apoptotic effect of immune cells in patients with endometriosis (44). BAX and BAK have been shown to be downregulated in patients with endometriosis, further demonstrating a notable role in the occurrence and development of endometriosis (45). The results of the present study showed that LDHA-knockdown promoted apoptosis of Ishikawa cells and THESC cells, suggesting that LDHA played a role in inhibiting apoptosis of endometrial cells.

Mitochondria are important organelles in the majority of cells and are closely associated with apoptosis (34). Generally, ATP levels and MMP decrease during apoptosis, whereas levels of ROS increase, indicating that mitochondrial function is impaired or decreased $(46,47)$. In mammalian cells, hypoxia induces dephosphorylation of FUN14 domain-containing protein 1 and enhances its interaction with LC3 to promote mitochondrial autophagy (48). The present study showed that after LDHA-knockdown, mitochondrial functions of THESC cells and Ishikawa cells were impaired, which may lead to apoptosis. In addition, hypoxia influenced THESC mitochondrial function but not that in Ishikawa cells; the specific mechanism remains unclear.

Increased expression of E-cadherin, a calcium-dependent adhesion molecule found on the surface of epithelial cells, may enhance the connection between cells, thus inhibiting their migratory and invasive abilities (49). Downregulated expression of E-cadherin has been reported to be potentially associated with susceptibility to endometriosis, resulting in elevated migration and invasion potentials of endometriotic cells (50). $\beta$-catenin protein localizes in the cell membrane and cytoplasm, where it is mainly involved in cell proliferation, differentiation and apoptosis (51). $\beta$-catenin can also bind to intracellular E-cadherin (52) to form an E-cadherin/ $\beta$-catenin complex that regulates cell adhesion and motility. Suppression of $\beta$-catenin expression has been shown to 
inhibit cell proliferation and migration, and promote apoptosis of mesenchymal cells in the endometrium, thus inhibiting the occurrence and development of endometriosis (53). The present study showed that LDHA-knockdown inhibited migration of Ishikawa cells and THESC cells, which was associated with increased E-cadherin expression and decreased $\beta$-catenin expression. These results indicated that LDHA promoted endometriotic cell migration in the progression of endometriotic cysts. LDHA is involved in the process of epithelial-mesenchymal transition and changes the ability of cells to migrate (54); however, how LDHA participates in the regulation of the relevant signaling pathways and affects downstream signaling molecules still needs further research.

Hypoxia may increase the expression of PDK1, a key enzyme in glucose metabolism, in ESCs, resulting in altered cell metabolism and lactic acid accumulation that inhibits apoptosis (11). The present study found that LDHA-knockdown in Ishikawa cells and THESC cells decreased lactic acid production and inhibited PDK1 expression, suggesting that glycolysis was inhibited. However, the current study did not confirm whether the effect of LDHA on lactic acid production was associated with its regulatory roles in apoptosis, cell cycle or cell motility.

In conclusion, the present study confirmed that LDHA was significantly increased in endometriotic tissues. Moreover, hypoxia-induced LDHA may serve an important role in the occurrence and development of endometriosis. Finally, LDHA-knockdown inhibited ESCs and glandular epithelial cell migration, promoted apoptosis and inhibited glycolysis.

\section{Acknowledgements}

Not applicable.

\section{Funding}

The present study was supported by grants from The National Natural Science Foundation of China (grant nos. 81871135, 81971358 and 81671435); Natural Science Foundation of Zhejiang Province (grant no. LY18H040008); National Key Research and Development Program (grant no. 2018YFC1004800); Key Research and Development Program of Zhejiang Province (grant no. 2017C03022); and The Medical and Health Program in Zhejiang Province (grant no. 2019KY411).

\section{Availability of data and materials}

All data generated or analyzed during this study are included in this published article.

\section{Authors' contributions}

JZ, YD and XL performed the experiments. JZ, XL, QH, LS, NL, FZ and XJ collected clinical samples, analyzed and interpreted the data. JZ and YD wrote the manuscript. YD made the figures. JZ, YD and SZ critically reviewed the article. JZ and YD confirm the authenticity of all the raw data. YD and
SZ conceived and supervised the project. All authors have read and approved the final manuscript.

\section{Ethics approval and consent to participate}

The present study was approved by The Ethics Committee of Sir Run Run Shaw Hospital at Zhejiang University. All patients provided written informed consent before sample collection.

\section{Patient consent for publication}

Not applicable.

\section{Competing interests}

The authors declare that they have no competing interests.

\section{References}

1. Bulun SE: Endometriosis. N Engl J Med 360: 268-279, 2009.

2. Batt RE: Invited comment on the paper by Benagiano et al: Entitled 'the history of endometriosis'. Gynecol Obstet Invest 78: $10-11,2014$

3. Shubina AN, Egorova AA, Baranov VS and Kiselev AV: Recent advances in gene therapy of endometriosis. Recent Pat DNA Gene Seq 7: 169-178, 2013.

4. Giudice LC and Kao LC: Endometriosis. Lancet 364: 1789-1799, 2004.

5. Wu MH, Chen KF, Lin SC, Lgu CW and Tsai SJ: Aberrant expression of leptin in human endometriotic stromal cells is induced by elevated levels of hypoxia inducible factor-1alpha. Am J Pathol 170: 590-598, 2007.

6. Hsiao KY, Lin SC, Wu MH and Tsai SJ: Pathological functions of hypoxia in endometriosis. Front Biosci (Elite Ed) 7: 309-321, 2015.

7. Lin X, Dai Y, Xu W, Shi L, Jin X, Li C, Zhou F, Pan Y, Zhang Y, Lin $\mathrm{X}$ and Zhang S: Hypoxia promotes ectopic adhesion ability of endometrial stromal cells via TGF- $\beta 1 /$ smad signaling in endometriosis. Endocrinology 159: 1630-1641, 2018.

8. Dai Y, Lin X, Xu W, Lin X, Huang Q, Shi L, Pan Y, Zhang Y, Zhu Y, Li C, et al: MiR-210-3p protects endometriotic cells from oxidative stress-induced cell cycle arrest by targeting BARD1. Cell Death Dis 10: 144, 2019

9. Young VJ, Brown JK, Maybin J, Saunders PT, Duncan WC and Horne AW: Transforming growth factor- $\beta$ induced Warburg-like metabolic reprogramming may underpin the development of peritoneal endometriosis. J Clin Endocrinol Metab 99: 3450-3459, 2014.

10. Molinari E, Bar H, Pyle AM and Patrizio P: Transcriptome analysis of human cumulus cells reveals hypoxia as the main determinant of follicular senescence. Mol Hum Reprod 22: 866-876, 2016

11. Lee HC, Lin SC, Wu MH and Tsai SJ: Induction of pyruvate dehydrogenase kinase 1 by hypoxia alters cellular metabolism and inhibits apoptosis in endometriotic stromal cells. Reprod Sci 26: 734-744, 2019.

12. Rong Y, Wu W, Ni X, Kuang T, Jin D, Wang D and Lou W: Lactate dehydrogenase A is overexpressed in pancreatic cancer and promotes the growth of pancreatic cancer cells. Tumour Biol 34: 1523-1530, 2013.

13. Koukourakis MI, Giatromanolaki A, Winter S, Leek R, Sivridis E and Harris AL: Lactate dehydrogenase 5 expression in squamous cell head and neck cancer relates to prognosis following radical or postoperative radiotherapy. Oncology 77: 285-292, 2009

14. Giatromanolaki A, Koukourakis MI, Pezzella F, Sivridis E, Turley H, Harris AL and Gatter KC: Lactate dehydrogenase 5 expression in non-Hodgkin B-cell lymphomas is associated with hypoxia regulated proteins. Leuk Lymphoma 49: 2181-2186, 2008.

15. Miao P, Sheng S, Sun X, Liu J and Huang G: Lactate dehydrogenase A in cancer: A promising target for diagnosis and therapy. IUBMB Life 65: 904-910, 2013. 
16. Semenza GL: HIF-1 mediates metabolic responses to intratumoral hypoxia and oncogenic mutations. J Clin Invest 123: 3664-3671, 2013.

17. Yeung SJ, Pan J and Lee MH: Roles of p53, MYC and HIF-1 in regulating glycolysis-the seventh hallmark of cancer. Cell Mol Life Sci 65: 3981-3999, 2008.

18. Holmes RS and Goldberg E: Computational analyses of mammalian lactate dehydrogenases: Human, mouse, opossum and platypus LDHs. Comput Biol Chem 33: 379-385, 2009.

19. Zhan L, Wang W, Zhang Y, Song E, Fan Y and Wei B: Hypoxia-inducible factor-1alpha: A promising therapeutic target in endometriosis. Biochimie 123: 130-137, 2016.

20. Griffiths EA, Pritchard SA, Valentine HR, Whitchelo N, Bishop PW, Ebert MP, Price PM, Welch IM and West CM: Hypoxia-inducible factor-1alpha expression in the gastric carcinogenesis sequence and its prognostic role in gastric and gastro-oesophageal adenocarcinomas. Br J Cancer 96: 95-103, 2007.

21. Sun HC, Qiu ZJ, Liu J, Sun J, Jiang T, Huang KJ, Yao M and Huang C: Expression of hypoxia-inducible factor-1 alpha and associated proteins in pancreatic ductal adenocarcinoma and their impact on prognosis. Int J Oncol 30: 1359-1367, 2007.

22. Maybin JA, Hirani N, Brown P, Jabbour HN and Critchley HO: The regulation of vascular endothelial growth factor by hypoxia and prostaglandin F2 $\alpha$ during human endometrial repair. J Clin Endocrinol Metab 96: 2475-2483, 2011.

23. Maybin JA, Hirani N, Jabbour HN and Critchley HO: Novel roles for hypoxia and prostaglandin E2 in the regulation of IL-8 during endometrial repair. Am J Pathol 178: 1245-1256, 2011.

24. D'Amico F, Skarmoutsou E, Quaderno G, Malaponte G, La Corte C, Scibilia G, D'Agate G, Scollo P, Fraggetta F, Spandidos DA and Mazzarino MC: Expression and localisation of osteopontin and prominin-1 (CD133) in patients with endometriosis. Int J Mol Med 31: 1011-1016, 2013.

25. He G, Jiang Y, Zhang B and Wu G: The effect of HIF-1alpha on glucose metabolism, growth and apoptosis of pancreatic cancerous cells. Asia Pac J Clin Nutr 23: 174-180, 2014.

26. Revised American Society for Reproductive Medicine classification of endometriosis: 1996. Fertil Steril 67: 817-821, 1997.

27. Ryan IP, Schriock ED and Taylor RN: Isolation, characterization, and comparison of human endometrial and endometriosis cells in vitro. J Clin Endocrinol Metab 78: 642-649, 1994.

28. Hsiao KY, Wu MH, Chang N, Yang SH, Wu CW, Sun HS and Tsai SJ: Coordination of AUF1 and miR-148a destabilizes DNA methyltransferase $1 \mathrm{mRNA}$ under hypoxia in endometriosis. Mol Hum Reprod 21: 894-904, 2015.

29. Hsiao KY, Chang N, Lin SC, Li YH and Wu MH: Inhibition of dual specificity phosphatase- 2 by hypoxia promotes interleukin-8-mediated angiogenesis in endometriosis. Hum Reprod 29: 2747-2755, 2014.

30. Livak KJ and Schmittgen TD: Analysis of relative gene expression data using real-time quantitative PCR and the 2(-Delta Delta C(T)) method. Methods 25: 402-408, 2001.

31. Chiappini F, Baston JI, Vaccarezza A, Singla JJ, Pontillo C, Miret N, Farina M, Meresman G and Randi A: Enhanced cyclooxygenase-2 expression levels and metalloproteinase 2 and 9 activation by Hexachlorobenzene in human endometrial stromal cells. Biochem Pharmacol 109: 91-104, 2016.

32. Wang D, Luo Y, Wang G and Yang Q: CircATRNL1 promotes epithelial-mesenchymal transition in endometriosis by upregulating Yes-associated protein 1 in vitro. Cell Death Dis 11: 594, 2020.

33. Cui XG, Han ZT, He SH, Wu XD, Chen TR, Shao CH, Chen DL, Su N, Chen YM, Wang T, et al: HIF1/2 $\alpha$ mediates hypoxia-induced LDHA expression in human pancreatic cancer cells. Oncotarget 8: 24840-24852, 2017.

34. Abate M, Festa A, Falco M, Lombardi A, Luce A, Grimaldi A, Zappavigna S, Sperlongano P, Irace C, Caraglia M, et al: Mitochondria as playmakers of apoptosis, autophagy and senescence. Semin Cell Dev Biol 98: 139-153, 2020.

35. Chen J, Liao W, Gao W, Huang J and Gao Y: Intermittent hypoxia protects cerebral mitochondrial function from calcium overload. Acta Neurol Belg 113: 507-513, 2013.
36. Wu MH, Hsiao KY and Tsai SJ: Hypoxia: The force of endometriosis. J Obstet Gynaecol Res 45: 532-541, 2019.

37. Kasvandik S, Samuel K, Peters M, Eimre M, Peet N, Roost AM, Padrik L, Paju K, Peil L and Salumets A: Deep quantitative proteomics reveals extensive metabolic reprogramming and cancer-like changes of ectopic endometriotic stromal cells. J Proteome Res 15: 572-584, 2016.

38. Gebel HM, Braun DP, Tambur A, Frame D, Rana N and Dmowski WP: Spontaneous apoptosis of endometrial tissue is impaired in women with endometriosis. Fertil Steril 69: 1042-1047, 1998.

39. Vaskivuo TE, Stenback F, Karhumaa P, Risteli J, Dunkel L and Tapanainen JS: Apoptosis and apoptosis-related proteins in human endometrium. Mol Cell Endocrinol 165: 75-83, 2000.

40. Singh R, Letai A and Sarosiek K: Regulation of apoptosis in health and disease: The balancing act of BCL-2 family proteins. Nat Rev Mol Cell Biol 20: 175-193, 2019.

41. Oltvai ZN and Korsmeyer SJ: Checkpoints of dueling dimers foil death wishes. Cell 79: 189-192, 1994.

42. Harada M, Suganuma N, Furuhashi M, Nagasaka T, Nakashima N, Kikkawa F, Tomoda Y and Furui K: Detection of apoptosis in human endometriotic tissues. Mol Hum Reprod 2: 307-315, 1996.

43. Meresman GF, Vighi S, Buquet RA, Contreras-Ortiz O, Tesone M and Rumi LS: Apoptosis and expression of Bcl-2 and Bax in eutopic endometrium from women with endometriosis. Fertil Steril 74: 760-766, 2000.

44. McLaren J, Prentice A, Charnock-Jones DS, Sharkey AM and Smith SK: Immunolocalization of the apoptosis regulating proteins $\mathrm{Bcl}-2$ and $\mathrm{Bax}$ in human endometrium and isolated peritoneal fluid macrophages in endometriosis. Hum Reprod 12: 146-152, 1997.

45. Depalo R, Cavallini A, Lorusso F, Bassi E, Totaro I, Marzullo A, Bettocchi S and Selvaggi L: Apoptosis in normal ovaries of women with and without endometriosis. Reprod Biomed Online 19: 808-815, 2009.

46. Zorov DB, Juhaszova M and Sollott SJ: Mitochondrial reactive oxygen species (ROS) and ROS-induced ROS release. Physiol Rev 94: 909-950, 2014.

47. Bulthuis EP, Adjobo-Hermans MJW, Willems $\mathrm{P}$ and Koopman WJH: Mitochondrial morphofunction in mammalian cells. Antioxid Redox Signal 30: 2066-2109, 2019.

48. Liu L, Feng D, Chen G, Chen M, Zheng Q, Song P, Ma Q, Zhu C, Wang R, Qi W, et al: Mitochondrial outer-membrane protein FUNDC1 mediates hypoxia-induced mitophagy in mammalian cells. Nat Cell Biol 14: 177-185, 2012.

49. Nagafuchi A, Shirayoshi Y, Okazaki K, Yasuda K and Takeichi M: Transformation of cell adhesion properties by exogenously introduced E-cadherin cDNA. Nature 329: 341-343, 1987.

50. Saliminejad K, Edalatkhah H, Kamali K, Memariani T, Nasiri M, Saket M and Khorram Khorshid HR: Association of common variations of the E-cadherin with endometriosis. Gynecol Endocrinol 31: 899-902, 2015.

51. Ma T, Fu B, Yang X, Xiao Y and Pan M: Adipose mesenchymal stem cell-derived exosomes promote cell proliferation, migration, and inhibit cell apoptosis via Wnt/beta-catenin signaling in cutaneous wound healing. J Cell Biochem 120: 10847-10854, 2019.

52. Hinck L, Nathke IS, Papkoff J and Nelson WJ: Dynamics of cadherin/catenin complex formation: Novel protein interactions and pathways of complex assembly. J Cell Biol 125: 1327-1340, 1994.

53. Zhang X, Liu Z, Chen M, Cao Q and Huang D: Effects of S100A6 gene silencing on the biological features of eutopic endometrial stromal cells and betacatenin expression. Mol Med Rep 15: 1279-1285, 2017.

54. Zhao J, Huang X, Xu Z, Dai J, He H, Zhu Y and Wang H: LDHA promotes tumor metastasis by facilitating epithelialmesenchymal transition in renal cell carcinoma. Mol Med Rep 16: 8335-8344, 2017.

This work is licensed under a Creative Commons Attribution-NonCommercial-NoDerivatives 4.0 International (CC BY-NC-ND 4.0) License. 